\title{
The Subpetrous Carotid Wall Hematoma: A Sign of Spontaneous Dissection of the Internal Carotid Artery on Non-Enhanced Computed Tomography - A Retrospective Study
}

\section{Das subpetröse Karotiswandhämatom: Ein Zeichen der spontanen Dissektion der Arteria carotis interna in der nativen kraniellen Computertomografie - Eine retrospektive Studie}

Authors

Affiliations

\author{
U. Jensen-Kondering ${ }^{1,2}$, M. Huhndorf ${ }^{1}$, J. Madjidyar ${ }^{1}$, O. Jansen ${ }^{1}$
}

Department of Radiology and Neuroradiology, University Hospital Schleswig-Holstein, Campus Kiel, Germany

Department of Neurology, University Hospital Schleswig-Holstein, Campus Kiel, Germany
Key words

- carotid arteries

- CT

- dissection

- ischemia/infarction

received $\quad 19.6 .2014$

accepted 2.9.2014

Bibliography

DOI http://dx.doi.org/

10.1055/s-0034-1385303

Published online: 6.11.2014

Fortschr Röntgenstr 2015; 187 :

168-172 @ Georg Thieme

Verlag KG Stuttgart - New York .

ISSN 1438-9029

\section{Correspondence}

Herr Dr. Ulf Jensen-Kondering

Department of Radiology and Neuroradiology, University

Hospital Schleswig-Holstein,

Campus Kiel

Arnold-Heller-Str. 3, Haus 41

24116 Kiel

Germany

Tel.: ++ 49/431/5974806

Fax: ++49/431/5974913

Ulf.Jensen-Kondering@uksh.de

\section{Zusammenfassung}

$\nabla$

Ziel: Spontane Dissektionen der A. carotis interna (DACI) sind eine zunehmend diagnostizierte Ursache für Schlaganfälle insbesondere bei jungen und mittelalten Patienten. Ziel der Arbeit war es, zu prüfen, ob die native kranielle Computertomografie (NCCT) das subpetröse Karotiswandhämatom darstellen kann und somit die Identifizierung von Patienten mit DACI ermöglicht.

Material und Methoden: Wir identifizierten retrospektiv Patienten mit DACI ( $n=21)$ sowie eine Kontrollgruppe $(n=42)$ von Patienten mit Symptomen einer zerebralen Ischämie, die alle ein NCCT bei Aufnahme erhielten. Zwei Neuroradiologen beurteilten unabhängig voneinander die Anwesenheit und Form des subpetrösen Karotiswandhämatom sowie den Durchmesser und Dichte der subpetrösen A. carotis interna. Zusätzlich wurde der Stenosegrad unterhalb der Schädelbasis mit der Form des subpetrösen Karotiswandhämatoms korreliert. Ergebnisse: Ein subpetröses Karotiswandhämatom konnte bei 14 von 21 Patienten (Cohens $\mathrm{k}=0,67$ ) identifiziert werden. Der mittlere Durchmesser der A. carotis interna betrug $6,95 \pm 1,05 \mathrm{~mm}$ im disseziierten Gefäß und $5,71 \pm 1,52 \mathrm{~mm}$ im nicht betroffenen kontralateralen Gefäß $(p<0,05)$. Der mittlere Dichteunterschied zwischen disseziierten und nicht disseziierten Gefäß betrug 15,05 $\pm 8,01$ $\mathrm{HU}(\mathrm{p}<0,01)$. Der mittlere Stenosegrad war signifikant höher $(21 \%$ vs. $80 \%$, p < 0,05) bei Patienten mit einem Karotiswandhämatom in Vollmondform $(\mathrm{n}=11)$ als in Mondsichelform $(\mathrm{n}=3)$.

Schlussfolgerung: Zwei Drittel der Patienten konnten mit dem NCCT korrekt identifiziert werden. Die extrakranielle ACI sollte bei Patienten mit Symptomen einer zerebralen Ischämie mitbeurteilt werden.

Kernaussagen:

- Wir analysierten Patienten mit einer Dissektion $(n=21)$ der A. carotis interna (DACI) und eine Kontrollgruppe $(n=42)$.

\section{Abstract \\ $\nabla$}

Purpose: Spontaneous dissection of the internal carotid artery (CAD) is an increasingly recognized cause for stroke especially in young and middleaged patients. We hypothesized that non-enhanced cranial computed tomography (NECCT) can visualize the subpetrous carotid wall hematoma and thus enable identification of patients with CAD.

Materials and Methods: We retrospectively reviewed patients with confirmed $\operatorname{CAD}(n=21)$ and a control group with ischemic symptoms but without CAD $(n=42)$ who received NECCT at admission. Two independent neuroradiologists rated the presence and shape of SPH, density and diameter of the subpetrous internal carotid artery. Additionally, we correlated the shape of the subpetrous carotid wall hematoma with the grade of stenosis on subsequent angiographic imaging.

Results: The subpetrous carotid wall hematoma was present in 14 of 21 patients (Cohen's $\mathrm{K}=0.67$ ). Mean diameter was $6.95 \pm 1.05 \mathrm{~mm}$ in dissected vessels and $5.71 \pm 1.52 \mathrm{~mm}$ in the contralateral vessel $(\mathrm{p}<0.05)$. Mean difference in vessel density was $15.05 \pm 8.01 \mathrm{HU}(\mathrm{p}<0.01)$. Median grade of stenosis was significantly higher in patients with a full moon- shaped $(n=11)$ than crescent-shaped $(n=3)$ subpetrous carotid wall hematoma ( $21 \%$ vs. $80 \%$, $\mathrm{p}<0.05$ ).

Conclusion: Two-thirds of patients with CAD were correctly identified on NECCT. The extracranial carotid artery should be evaluated in patients with symptoms of cerebral ischemia.

Key points

- We retrospectively reviewed patients with carotid artery dissection $(\mathrm{n}=21)$ and a control group $(n=42)$.

- The subpetrous carotid wall hematoma was present in two-thirds of patients with CAD but only in two control patients. 
- Die Anwesenheit und Form des subpetrösen Karotiswandhämatoms wurden bewertet.

- Ein subpetröses Karotiswandhämatom war bei zwei Dritteln der Patienten mit DACI vorhanden.

- Das subpetröse Karotiswandhämatom ist ein wertvolles Zeichen zur Identifizierung von Patienten mit DACI.
- The subpetrous carotid wall hematoma is a valuable sign to identify patients with CAD.

Citation Format:

- Jensen-Kondering U, Huhndorf M, Madjidyar J et al. The Subpetrous Carotid Wall Hematoma: A Sign of Spontaneous Dissection of the Internal Carotid Artery on Non-Enhanced Computed Tomography - A Retrospective Study. Fortschr Röntgenstr 2015; 187: $168-172$

\section{Introduction}

$\nabla$

Spontaneous dissection of the cervical brain-supplying artery is a common cause of stroke in young and middle-aged patients and accounts for up to $25 \%$ of strokes in that age group [1]. As imaging techniques mature and cross-sectional imaging is widely available, it is increasingly recognized and more easily diagnosed. The typical clinical presentation of dissection of the internal carotid artery (CAD) is the combination of lateral neck pain with ipsilateral Horner's syndrome associated with ischemic symptoms. Only one-fourth of patients present with neck pain. Complete or partial Horner's syndrome is present in less than half of patients. However, ischemia occurs in up to $90 \%$ of patients [2]. Definite diagnosis is thus crucial for specific therapy and requires direct visualization of the mural hematoma with cross-sectional imaging techniques $[4,5]$ or indirect visualization as flameshaped tapering of the carotid artery with angiographic techniques, such as digital subtraction angiography (DSA) [3], computed tomography angiography (CTA) or magnetic resonance angiography (MRA). On T1w images the mural hematoma containing methemoglobin appears hyperintense in the subacute stage from day three onward [6]. Nowadays, MRI is surpassing other imaging techniques for its increasing resolution and sensitivity for very small mural hematomas.

It was recently demonstrated that most patients with CAD can be diagnosed on routine MRI without dedicated vessel imaging [7]. Non-enhanced cranial computed tomography (NECCT) can reliably identify hemorrhage, thrombi [8] and early ischemic signs [9]. NECCT remains the first-line imaging tool in many specialized stroke centers and is widely available even in non-specialized institutions. As the mural hematoma extends to the skull base in most cases, we speculated that CAD can be diagnosed on NECCT in most patients by visualization of a subpetrous carotid wall hematoma since the uppermost part of the internal carotid artery directly in front of its entry into the carotid canal is included on the lowermost slices on most NECCT scans.

\section{Materials and Methods}

$\nabla$

\section{Patients and Imaging}

The study was approved by the local ethics committee and patients consented to analysis of the data. We retrospectively included consecutive patients within a five-year period (2008 - 2013) with a confirmed spontaneous CAD with a mural hematoma reaching the skull base who underwent NECCT at admission. CAD was considered confirmed if one or both of the following was present 1) mural hematoma demonstrated on CTA or T1 w imaging 2) flame-shaped tapering without other explanation on any angiographic imaging technique (CTA, MRA, DSA). The scanning parameters using a multidetector row $\mathrm{CT}$ scanner with 64 detector rows ("Brilliance 64", Philips, Best, The Netherlands) were as follows: collimation $16 \times 0.625 \mathrm{~mm}$, tube voltage $120 \mathrm{kV}$, tube current $320 \mathrm{mAs}, 2.5 \mathrm{~mm}$ reconstructed slice thickness. Demographics and clinical information were extracted from the patients' charts.
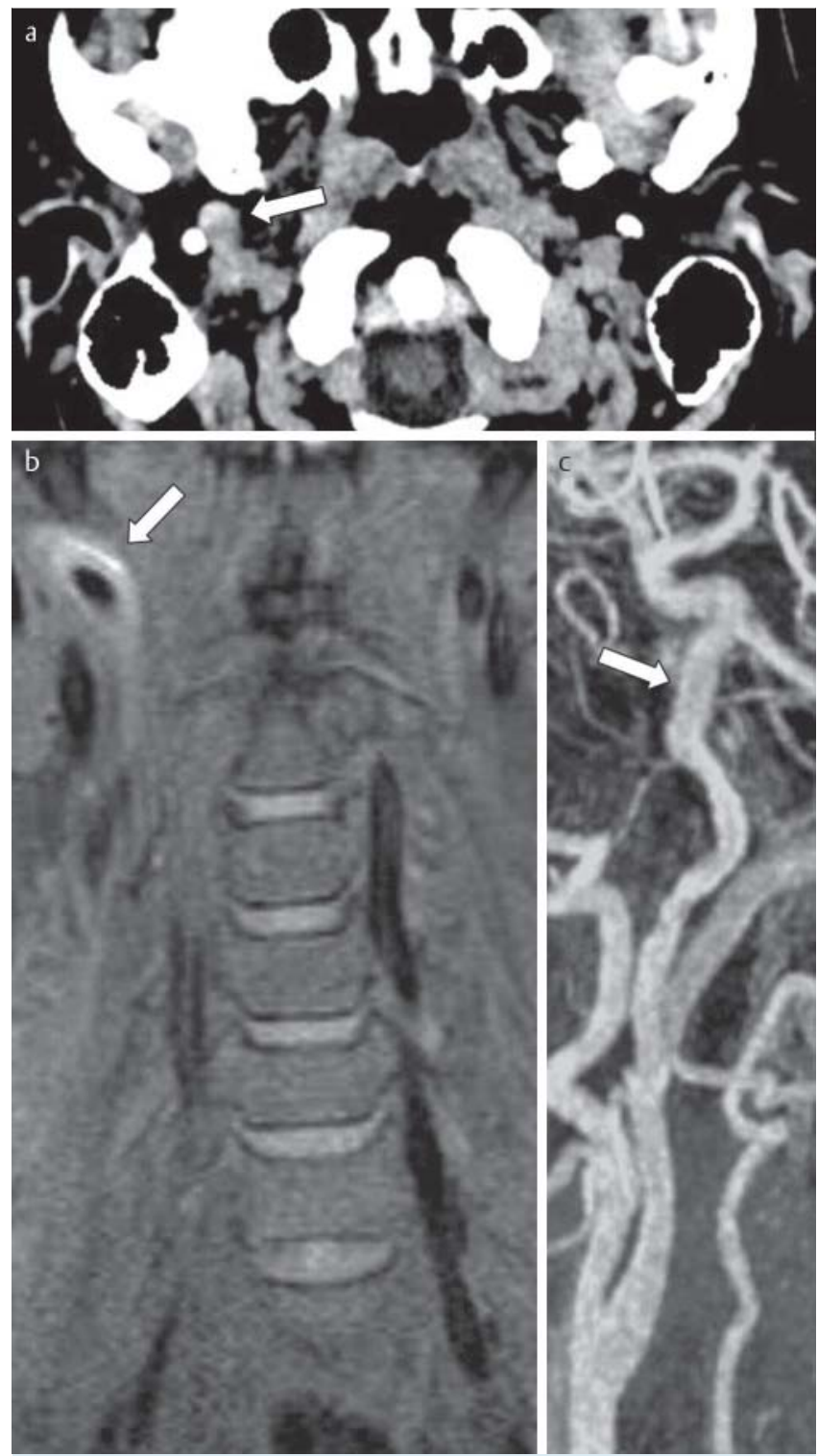

Fig. 1 Right-sided crescent-shaped subpetrous carotid wall hematoma a. Coronal T1w fat-saturated image demonstrates a mural hematoma $\mathbf{b}$. No relevant stenosis is visible on contrast-enhanced MRA c.

Abb. 1 Rechtsseitiges mondsichelförmiges subpetröses Karotiswandhämatom a. Die koronare fettgesättigte T1w-Schicht zeigt das Wandhämatom $\mathbf{b}$. In der MRA ist keine relevante Stenose sichtbar c. 


\section{Image analysis}

Two independent neuroradiologists blinded to the presence of CAD and lesion side rated the subpetrous carotid wall hematoma as either absent or present. Disagreement was resolved in a panel session. We could identify two types of subpetrous carotid wall hematoma: the classic crescent or half moon-shaped hematoma ( $\bullet$ Fig. 1) and a full moon-shaped hematoma ( $\bullet$ Fig. 2, 3). A full moon-shaped subpetrous carotid wall hematoma was defined as the presence of an enlarged and hyperdense internal carotid artery compared to the contralateral side. The crescent-shaped subpetrous carotid wall hematoma was defined as a hyperdense crescent or half moon adjacent to or encompassing the arterial
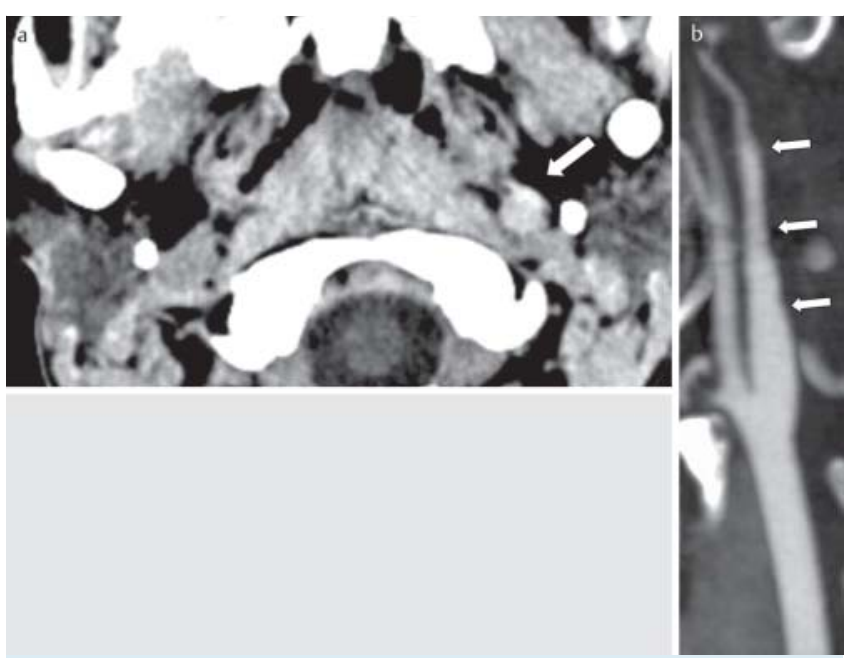

Fig. 2 Left-sided full moon-shaped subpetrous carotid wall hematoma a. Reconstructed CTA $\mathbf{b}$ demonstrates tapered lumen of the ICA (arrows).

Abb. 2 Linksseitiges vollmondförmiges subpetröses Karotiswandhämatom a. Die rekonstruierte CTA b zeigt das sich verjüngende Lumen der A. carotis interna (Pfeile).

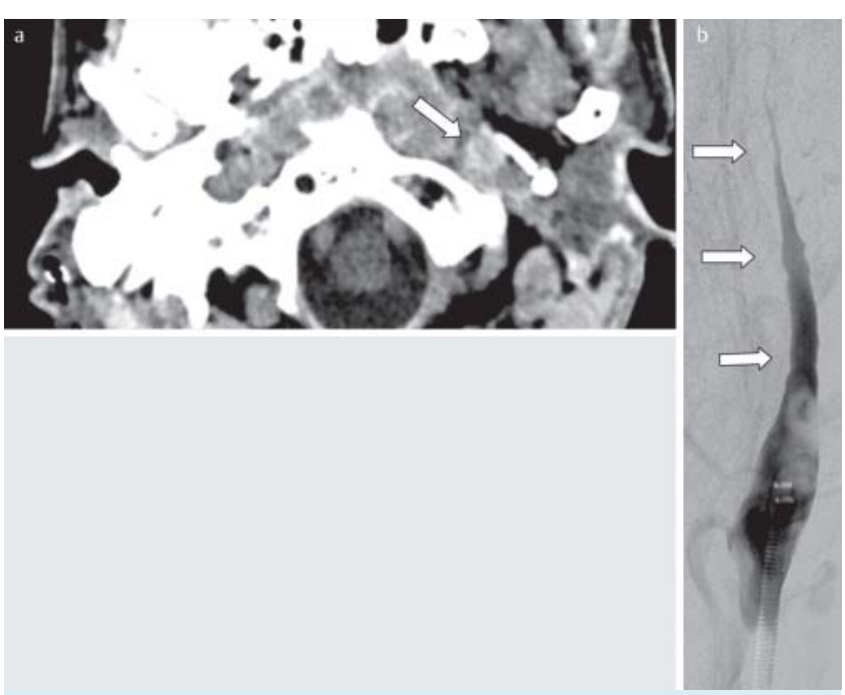

Fig. 3 Left-sided full moon-shaped subpetrous carotid wall hematoma a. DSA $\mathbf{b}$ with injection into the left proximal ICA demonstrates tapered lumen (arrows).

Abb. 3 Linksseitiges vollmondförmiges subpetröses Karotiswandhämatom a. Die DSA b mit Injektion in die linke proximale A. carotis interna zeigt das sich verjüngende Lumen (Pfeile). lumen. The fullmoon-shaped subpetrous carotid wall hematoma was defined as the presence of an enlarged and hyperdense internal carotid arterycompared to the contralateral side. The shape of the hematoma was determined in consensus in a subsequent session. As a secondary analysis, the diameter of the internal carotid artery and the density of the subpetrous carotid wall hematoma were measured in consensus by the two observers. Additionally, the correlation between the density of the subpetrous carotid wall hematoma and presumed age of the hematoma was calculated as it is known that hematoma density decreases with time.

A third rater blinded to the shape of the hematoma took a measurement of the resulting stenosis just below the skull base. If more than one angiographic technique was performed, DSA was preferred to CTA and CTA to MRA. The grade of stenosis (in \%) was calculated according to the NASCET criteria by subtraction of the minimal luminal diameter at the skull base from the normal appearing proximal luminal diameter, divided by the normal luminal diameter and multiplied by 100 [10].

\section{Statistics}

SPSS version 15.0 (IBM Corporation, Somers/NY, USA) was used. Agreement between raters was calculated using Cohen's $\mathrm{k}$. Values below 0 were defined as poor, $0-0.20$ as slight, $0.21-0.40$ as fair, $0.41-0.60$ as moderate, $0.61-0.80$ as substantial and $0.81-1.00$ as (almost) perfect agreement.

All comparisons were made using a two-tailed Whitney-Mann U-test. The level of significance was set at $\mathrm{p}<0.05$.

Sensitivity was calculated as the number of true positives divided by the sum of true positives and the number of false negatives. Specificity was accordingly calculated as the number of true negatives divided by the sum of true negatives and the number of false positives.

\section{Results}

$\nabla$

21 patients (10 female, 11 male patients, mean age $48 \pm 8$ years) could be included. Only one patient with CAD with the subpetrous carotid wall hematoma not reaching the skull base and meeting all inclusion criteria could be identified but was excluded. As a control group, an age and sex-matched cohort of patients $(n=42)$ undergoing NECCT for ischemic symptoms but without CAD was used. Median time to presentation was 24 hours (range: 45 minutes to 4 weeks). Of the 21 patients, 14 patients with CAD exhibited a subpetrous carotid wall hematoma while only two without a CAD did. In three patients with CAD the subpetrous region on the affected side was not included in the field of view because the acquisition plane was slightly tilted. Interrater agreement was substantial with $\mathrm{K}=0.67$. This results in a sensitivity of $67 \%$ and a specificity of $95 \%$. When excluding the patients without coverage of the subpetrous region, sensitivity increased to $78 \%$.

3 patients exhibited a crescent-shaped subpetrous carotid wall hematoma, and 11 had a full moon-shaped subpetrous carotid wall hematoma. DSA was performed in 3 patients, CTA in another 3 and MRA in 7 patients. Median grade of stenosis was $80 \%$ in patients with a full moon-shaped subpetrous carotid wall hematoma and $21 \%$ with a crescent-shaped subpetrous carotid wall hematoma ( $\mathrm{p}<0.05)$. Mean diameter was $6.95 \pm 1.05 \mathrm{~mm}$ in dissected vessels and $5.71 \pm 1.52 \mathrm{~mm}$ in the contralateral vessel $(\mathrm{p}<0.05)$. Mean difference in vessel density was $15.05 \pm 8.01 \mathrm{HU}(\mathrm{p}<0.01)$. 


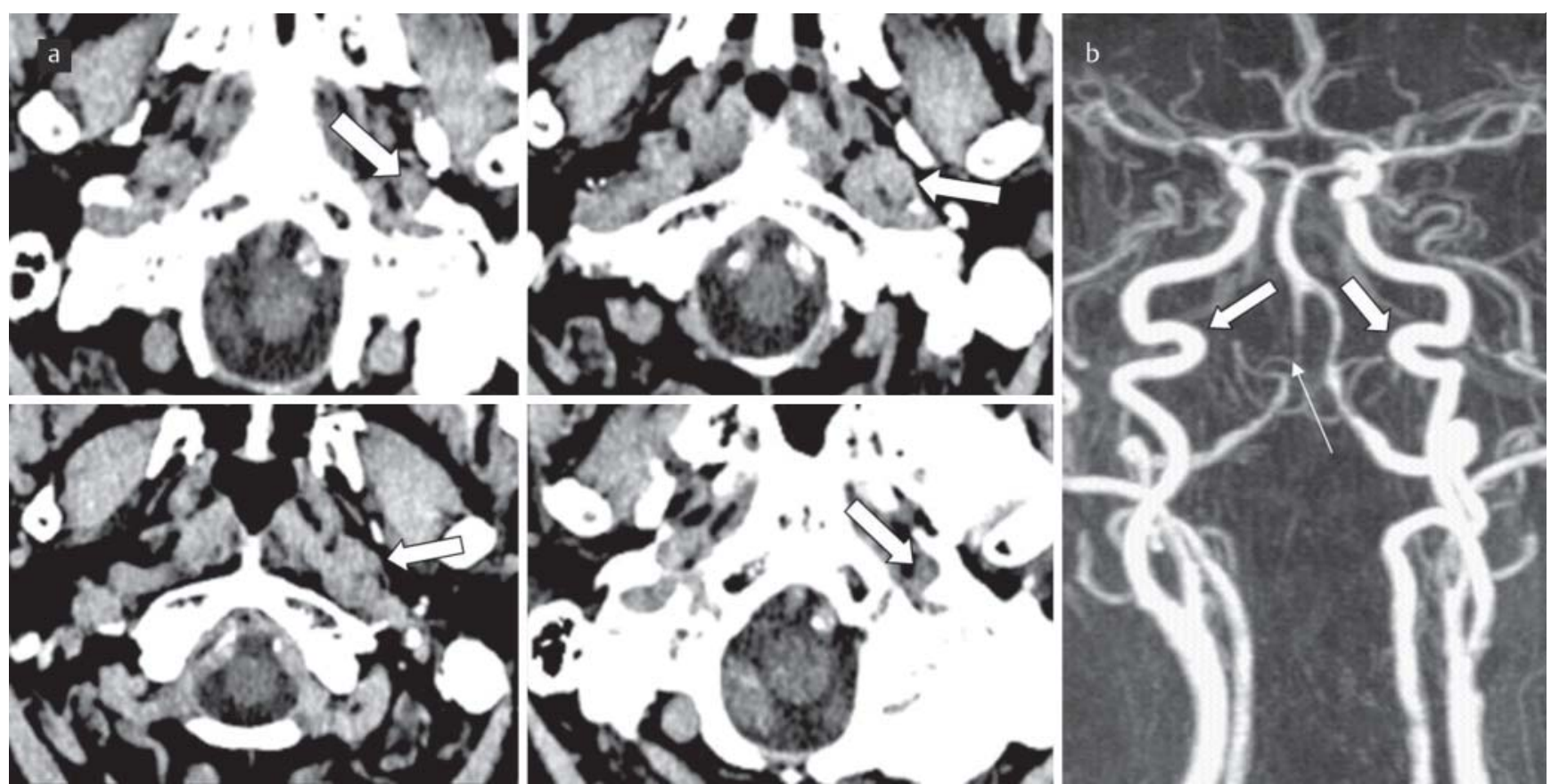

Fig. 4 False-positive subpetrous carotid wall hematoma. The internal carotid artery appears enlarged and hyperdense but can be followed along its tortuous course below the skull base a. Contrast-enhanced MRA in the same patient demonstrates an elongated and tortuous course of the internal carotid artery below the skull base $\mathbf{b}$. Note stenosis of the right vertebral artery (long arrow).
Abb. 4 Falsch positives subpetröses Karotiswandhämatom. Die A. carotis interna erscheint vergrößert und hyperdens, kann aber entlang ihres gewundenen Verlaufs unterhalb der Schädelbasis verfolgt werden a. Die kontrastmittelverstärkte MRA beim selben Patienten zeigt den elongierten und gewundenen Verlauf der A. carotis interna unterhalb der Schädelbasis b. Nebenbefundlich Stenose der rechten A. vertebralis (langer Pfeil).
The onset of symptoms with regards to non-ischemic symptoms of CAD was recorded only in a minority of patients while the time to presentation with regard to ischemic symptoms was recorded in all patients. Thus, a correlation between density and the presumed age of the hematoma could not be calculated.

\section{Discussion \\ $\nabla$}

We found that two-thirds of patients with CAD were correctly identified with NECCT. Our secondary analysis confirmed our subjective ratings. All findings on NECCT could be easily identified on the standard 40/80 (width/level) window setting. Since the subpetrous carotid wall hematoma was only rated as present in two patients without CAD, the specificity of this sign was very high. A possible mechanism for a false-positive subpetrous carotid wall hematoma is a tortuous course of the internal carotid artery. If the artery is not running perpendicular to the imaging plane, it may be mistaken for an enlarged vessel but it can be identified if followed continuously through the imaging stack (o Fig. 4).

Dissection of the cervical brain-supplying arteries is a sequela of intimal tears. Blood can enter the space between the intimal and media layers and cause local stenosis or occlusion. The mural hematoma usually occurs a few centimeters distal to the bifurcation and extends to the subpetrous segment and to the skull base. It rarely enters the skull as the carotid canal forms a natural barrier. The intimal tear itself represents the location for thrombus formation and subsequent embolization. The standard treatment for extradural CAD is oral anticoagulation for at least 3-6 months. For a review on the pathogenesis, clinical presentation, diagnosis and treatment, see Schievink [11]. Intravenous throm- bolysis was demonstrated to be safe in patients with CAD [12, 13]. However, in patients with CAD and local high-grade stenosis or occlusion, mechanical recanalization is a potentially more efficient option to consider $[14,15]$.

The crescent sign was described in the aorta as a cap of hyperattenuating thrombus material suggesting acute or impending dissection [16]. It was also described on T1w images in subacute dissection of the vertebral and internal carotid arteries [17]. One case report describes its presence on NECCT in a patient with CAD [18]. To our knowledge, the present work is the first systematic report on the prevalence and significance of this sign in patients with CAD.

There are several limitations to this study. The retrospective character of the study and the small sample size do not allow for general conclusions. Additionally, a suspicious or definite pathologic NECCT will not replace vessel imaging. However, especially in patients without suspicion of dissection, this sign could entail further vascular work-up. The difference between the two observed shapes of the subpetrous carotid wall hematomas is not clear and the immediate consequences are the same. However, there was at least a trend towards higher grades of stenosis in the case of the full moon-shaped subpetrous carotid wall hematoma. Both shapes should be appreciated if encountered.

\section{Conclusion \\ $\nabla$}

The subpetrous hematoma on NECCT could be used as an early marker of CAD. This report demonstrates that NECCT can deliver information on extracranial vessel status. It also serves as a reminder as to how much information is available on NECCT. Attention should be paid to the extracranial portions of the internal 
carotid artery if included on NECCT especially in young and middle-aged patients with ischemic symptoms. The presence of a subpetrous carotid wall hematoma should entail further vascular work-up.

\section{Clinical Relevance of the Study}

- Dissections of the cervical brain-supplying vessels are an important differential diagnosis for causes of ischemic stroke in young and middle-aged patients.

- Although the diagnosis can currently be made with MRI, computed tomography remains the most used imaging modality.

- The subpetrous carotid wall hematoma can be detected in a majority of patients with dissection of the internal carotid artery on unenhanced computed tomography.

\section{References}

1 Ducrocq X, Lacour JC, Debouverie $M$ et al. Cerebral ischemic accidents in young subjects. A prospective study of 296 patients aged 16 to 45 years. Rev Neurol (Paris) 1999; 155: 575-582

2 Silbert PL, Mokri B, Schievink WI. Headache and neck pain in spontaneous internal carotid and vertebral artery dissections. Neurology 1995; 45: 1517-1522

3 Houser OW, Mokri B, Sundt TM Jr et al. Spontaneous cervical cephalic arterial dissection and its residuum: angiographic spectrum. AJNR Am J Neuroradiol 1984; 5: 27 -34

4 Leclerc X, Godefroy O, Salhi A et al. Helical CT for the diagnosis of extracranial internal carotid artery dissection. Stroke 1996; 27: 461 - 466

5 Lévy C, Laissy JP, Raveau V et al. Carotid and vertebral artery dissections: three-dimensional time-of-flight MR angiography and MR imaging versus conventional angiography. Radiology 1994; 190: 97-103
6 Fiebach J, Brandt T, Knauth M et al. MRI with fat suppression in the visualization of wall hematoma in spontaneous dissection of the internal carotid artery. Fortschr Röntgenstr 1999; 171: 290-293

7 Naggara O, Soares F, Touze E et al. Is it possible to recognize cervical artery dissection on stroke brain MR imaging? A matched case-control study. AJNR Am J Neuroradiol 2011; 32: 869-873

8 Jensen-Kondering $U$, Riedel C, Jansen 0 . Hyperdense artery sign on computed tomography in acute ischemic stroke. World J Radiol 2010; 2: $354-357$

9 von Kummer R, Holle R, Gizyska $U$ et al. Interobserver agreement in assessing early CT signs of middle cerebral artery infarction. AJNR Am J Neuroradiol 1996; 17: $1743-1748$

10 North American Symptomatic Carotid Endarterectomy Trial (NASCET) Steering Committee. North American Symptomatic Carotid Endarterectomy Trial: Methods, patient characteristics, and progress. Stroke 1991; 22: $711-720$

11 Schievink WI. Spontaneous dissection of the carotid and vertebral arteries. N Engl J Med 2001; 344: 898 -906

12 Derex L, Nighoghossian N, Turjman F et al. Intravenous tPA in acute ischemic stroke related to internal carotid artery dissection. Neurology 2000; 54: 2159-2161

13 Georgiadis $D$, Lanczik 0 , Schwab $S$ et al. IV thrombolysis in patients with acute stroke due to spontaneous carotid dissection. Neurology 2005; 64: $1612-1614$

14 Lavallée PC, Mazighi M, Saint-Maurice JP et al. Stent-assisted endovascular thrombolysis versus intravenous thrombolysis in internal carotid artery dissection with tandem internal carotid and middle cerebral artery occlusion. Stroke 2007; 38: 2270-2274

15 Yin Q, Li Y, Fan X et al. Feasibility and safety of stenting for symptomatic carotid arterial dissection. Cerebrovasc Dis 2011; 32: 11-15

16 Siegel CL, Cohan RH, Korobkin $M$ et al. Abdominal aortic aneurysm morphology: CT features in patients with ruptured and nonruptured aneurysms. Am J Roentgenol Am J Roentgenol 1994; 163: 1123 - 1129

17 Kirsch E, Kaim A, Engelter $S$ et al. MR angiography in internal carotid artery dissection: improvement of diagnosis by selective demonstration of the intramural haematoma. Neuroradiology 1998; 40: 704-709

18 Bugnicourt JM, Monet-Desblache P, Deramond $H$ et al. The "carotid CT crescent" sign. Clin Neurol Neurosurg 2012; 114: 803-805 